\title{
Evaluation study on level of trust in Water Conservancy Projects
}

\author{
Lei Guo ${ }^{1,2, a}$, Han $\operatorname{Han}^{1,2, b}$ \\ 1 School of Water Conservancy, \\ North China Institute of Water Conservancy and Hydroelectric Power, \\ Zhengzhou 450045, China \\ 2 Collaborative Innovation Center of Water Resources Efficient Utilization and Protection \\ Engineering, Henan Province \\ aglboss@126.com, b378423126 @qq.com,
}

\begin{abstract}
Keywords: water conservancy projects; trust; confidence indicators; level of trust.
Abstract. The trust level between the owners and contractors is the key factor for project succeed in water conservancy projects. In order to study the level of trust between the owner and the contractor, this paper analysis the indicators of inter-organizational trust level and designs questionnaires according to the indicators and distributes the questionnaires to the owners and contractors .After analysis the results from the questionnaires, this paper gives the trust level between the owner and the contractor in water conservancy projects. The analysis results of the questionnaires show that the trust level between the owners and contractors is not too high and not achieve the desired results. There is no significant difference in the calculus-based trust between the owners and contractors and relational trust reveals significant difference. Overall, there is no significant difference between the trust from the owners to the contractors and the trust from the contractors to the owners.
\end{abstract}

\section{Introduction}

In water conservancy construction projects, trust between the owner and contractor has generated which is needed on cooperation between owners and contractors. Trust between organizations has influence on cooperative performance, direct effects generated by trust is greater than the indirect impact of commitment ${ }^{[1]}$, so trust is considered to be the adhesive between owners and contractors and this relationship is the key to project success ${ }^{[2]}$. The two sides not only establish cooperation in specific provisions ,but also continue to seek trust in order to achieve optimal cooperation in the process of cooperation. From the literature of water conservancy construction about trust , trust can be divided into computational trust, relational trust and institutional trust and include antecedents of trust, trust, the overall success of the project theoretical model ${ }^{[3]}$. In hydraulic engineering projects, the effect factors of trust is divided into characteristics of the trusted party and characteristics of the both sides .The characteristics of the trusted includes credit, ability, the consistency of words and deeds ${ }^{[4]}$ and the characteristics of the both sides includes communication, reciprocity and contract ${ }^{[5]}$.

This paper aimed to get the level of the trust between owners and contractors through the research of the trust between owners and contractors in water conservancy construction projects recently and improve the level of the both sides and improve cooperation between the two sides performance and reduce transaction costs, establishing a harmonious cooperative relationship.

\section{Identified of trust indicators}

The characteristics of the trusted party is the because of the characteristics of the trusted party leading to the trust of the other party. In water conservancy construction projects, in the study of the relationship between trusted party and trust, the characteristics of the trusted party includes credit, ability, the consistency of words and deeds ${ }^{[4]}$.

The credit is the evaluation of the public to somebody and attributed to someone or something unique features or characteristics ${ }^{[5,6]}$. The credit is the intangible assets which has the plasticity, valuable, sustainable and is an effective tool for strategic advantage in the market of fierce 
competition. The credibility of the trusted party is better and the trust from the other side is higher, the credibility and trust is positive correlation. So this paper takes the credit as the indicators of the trust.

The ability is the subjective conditions to complete an activity successfully through themselves efforts and it is always related to the completion of certain activities. The ability can be divided into group capacity and individual capacity. This paper according to group capacity and individual capacity to get the level of the trust.

The words and deeds between owners and contractors can promote mutual trust. The words and deeds between owners and contractors and trust is positive correlation ${ }^{[7]}$. So this paper takes the words and deeds as the indicators of the trust.

The characteristics of the both sides is the trusted party and the party of mutual cooperation shown the other side of the characteristics of their trust. The characteristics of the both sides include communication, reciprocity and contract ${ }^{[5]}$.

In water conservancy construction projects, communication can promote the generating of the trust. The good communication can reduce the conflict. So this paper takes the communication as the indicators of the trust.

Mutuality means that either the owner and the contractor makes a help or contribution, the other party should be rewarded on the other side that is equally beneficial actions. In water conservancy construction projects, owners and contractors obtain their respective interests through advantage of each other. So the mutuality of the owner and the contractor is the important role of the trust.

Contract is intended to prevent potential opportunistic behavior. Generally, Signing a strict contract can reduce the incidence of opportunistic behavior and ensure the both sides complete the cooperation according to the established way ${ }^{[8]}$. The contract helps the building of trust.

\section{Research methods}

The purpose of this paper is to obtain the overall level of trust between the owners and contractors in water conservancy construction projects. This paper mainly uses the questionnaire method in the process of the study. By designing a questionnaire to collect data of the current level of trust and get the level of the trust between the owners and contractors.

This paper designs the relevant questionnaire based on the principle of questionnaire design ${ }^{[9]}$ and consult the professional teacher to get the final questionnaire. Design different questionnaires according to the owners and contractors when designing the questionnaire and build the questionnaire in Internet (www.wenjuan.com).

The survey proceeds from April 2015 to May 2015 and collects 180 questionnaires with owners and contractors questionnaires each 80 and invalid 20 questionnaires.

\section{Data analysis}

The reliability of the questionnaire is the reliability of the questionnaire. The analysis of the credibility of the questionnaire is mainly used in the Alpha reliability coefficient method.

In order to ensure the reliability and validity of the questionnaire, we use SPSS software to analyze the reliability of the two questionnaires.

Table 1. Results of the questionnaire of business owners on the contract

\begin{tabular}{ccc}
\hline Cronbach's Alpha & Alpha Cronbach's based on standard terms & Number of items \\
\hline 0.935 & 0.935 & 20 \\
\hline
\end{tabular}

Table2. The reliability analysis of the results of the survey conducted by the contractor on the owner 's trust degree

Cronbach's Alpha

Alpha Cronbach's based on standard terms

Number of

0.930

0.931

items 
Seen from the table1 and table2, the overall reliability of the Alpha Cronbach's were 0.935 and 0.930 which were more than 0.80 . Therefore, the results of the two questionnaires were passed the reliability test, we can think that these two questionnaires are scientific and effective.

For the Contractor's questionnaire survey of the owner, the largest of the field is management, the work time of the subject of the mostconcentrated in 5 to 10 years, on-site management personnel is directly exposed to the construction site, staff on-site survey and supervision have a set of work experience, so the survey object can represent the current owners of the overall level.

The single factor variance is used to analyze whether the mean value of a single variable has a significant difference. In this paper, the author analyzes the differences between the owner and the contractor, and then considers the difference between the owner and the contractor. Variance homogeneity test is an important prerequisite for the analysis of variance, and it is a condition for the application of the principle of variance. Homogeneity test is the test of whether the variance of the two sample is the same. From the table 3-3 can see the results of the homogeneity of variance, from the table can be obtained from the Lenvene of the of the $\mathrm{P}$ value is 0.096 , the big 0.05 at a significant level of 5, so that the owner and the contractor between the variance is homogeneous. So the distribution of the variance of the two samples is the same.

Table 3.Calculation based trust variance homogeneity test.

\begin{tabular}{cccc}
\hline $\begin{array}{c}\text { Levene } \\
\text { Statistic }\end{array}$ & df1 & df2 & Significant \\
\hline .002 & 1 & 158 & .096 \\
\hline
\end{tabular}

Table4 gives a single factor analysis of variance results from the table we can see that the sum of squares between groups is 0.061 , the sum of the squares and is 56.559 , the sum of squares and the F-measure is 0.170 , the corresponding probability is 0.068 , greater than 0.05 , so we think there is no significant impact between the owners and contractors.

Table 4. Single factor analysis of variance

\begin{tabular}{lccccc}
\hline & Square sum & df & Mean square & F & Significant. \\
\hline Group & .061 & 1 & .061 & .170 & .068 \\
(combination) & .061 & 1 & .061 & .170 & .068 \\
In the group & 56.669 & 158 & .359 & & \\
Total & 56.730 & 159 & & & \\
\hline
\end{tabular}

Table 5 gives the results of the homogeneity of variance, from which the $\mathrm{P}$ value of the homogeneity test of Levene variance is 0.269 , which is more than 0.05 , so it can be considered that the variance of sample data is homogeneous. So the distribution of the variance of the two samples is the same.

Table 5.Relational trust variance homogeneity test

\begin{tabular}{cccc}
\hline $\begin{array}{c}\text { Levene } \\
\text { Statistic }\end{array}$ & $\mathrm{df} 1$ & $\mathrm{df2}$ & Significant \\
\hline 1.228 & 1 & 158 & .269 \\
\hline
\end{tabular}

Table 6 gives a single factor analysis of variance results from the table we can see that the square and the group is 63.780 , the sum of the square and the 0.274 , the group is 64.780 , the corresponding probability is 0.041 , less than a significant level of 0.05 , so we believe that the relationship between the owner and the contractor has a significant impact. 
Table 6. Single factor analysis of variance

\begin{tabular}{lcccccc}
\hline & \multicolumn{3}{c}{ Mean } \\
& Square sum & df & & square & F & Significant. \\
\hline Group(combination) & .274 & 1 & .274 & .680 & .041 \\
& Linear term & .274 & .274 & .061 & .680 & .041 \\
In the group & 63.780 & 158 & .404 & & \\
Total & 64.055 & 159 & & & \\
\hline
\end{tabular}

In the same way, the author analyzes the difference between the trust and the trust of the owner to the owner. Table 7 gives the results of the homogeneity test. The $\mathrm{P}$ value of the Levene is 0.062 , which is more than 0.05 . So the distribution of the variance of the two samples is the same.

Table 7. Total variance test

\begin{tabular}{cccc}
\hline $\begin{array}{c}\text { Levene } \\
\text { Statistic }\end{array}$ & df1 & df2 & Significant \\
\hline .273 & 1 & 158 & .062 \\
\hline
\end{tabular}

Table 8 shows the results of single factor analysis of variance, from the table we can see that the square and the group is 55.984, the sum of the squares and the 56.026, the 0.041 , the corresponding probability is 0.073 , greater than 0.05 , so we believe that there is no significant difference between the trust and the trust between the contractor and the owner.

Table 8. Single factor analysis of variance

\begin{tabular}{|c|c|c|c|c|c|}
\hline & Square sum & df & $\begin{array}{l}\text { Mean } \\
\text { square }\end{array}$ & $\mathrm{F}$ & Significant. \\
\hline Group(combination) & .041 & 1 & .041 & .117 & .073 \\
\hline Linear term & .041 & 1 & .041 & .117 & .073 \\
\hline In the group & 55.984 & 158 & .354 & & \\
\hline Total & 56.026 & 159 & & & \\
\hline
\end{tabular}

\section{Conclusions}

The following main conclusions are obtained.

(1)According to the results of the questionnaire survey, trust level of the current domestic water conservancy construction industry between the owner and the contractor is not high, did not achieve the desired goal. The trust between the organization and the two sides have not been very good to bring higher performance.

(2)Seen from the final results of the analysis, whether the questionnaire survey results of Trust degree by the contractor to the owners or by the contractor to the owners, the mean value of the computational trust is the highest but the mean value of relational trust is lower. So we should pay more attention to the cultivation of relational trust in future cooperation.

Since trust has a very important role in improving the performance between the owner and the contractor, the higher the degree of trust in the organization, the higher the degree of satisfaction of the alliance ${ }^{[10]}$. Therefore, the owner and the contractor should choose the reasonable management method in the process of cooperation, effectively improve the trust between the owner and the contractor. This paper proposes the following ideas, as a way to improve the trust of both parties

(1) the establishment of reputation information dissemination platform;

(2) construction of project communication mechanism. 


\section{References}

[1] Pan Wenan, Zhang Hong. commitment on cooperative performance influence between the partners in the supply chain of trust, [J] Psychological science, 2006, 29 (6): 1502 - 1506.

[2] Bresnen M, Marshall N.Building partnerships: case studies of client-contractor collaboration in the UK construction industry[J].Construction Management and Economics，2000，18（7）: 819-832.

[3] Yue Yun, Jiang Weiping, Research on the mechanism of trust in construction [J]. Academic research 2010.3 (2): 56-60.

[4] Jiang Weiping, Zhang Qian, Le cloud, the generation of trust and influence of the engineering projects based on the owner's side view [J]. academic research, 25, 2011 (2): 181.

[5] Seymore D, Rooke J.The culture of the industry and the culture of research[J].Construction Management and Economics, 1995, 13 (5) : 511-523.

[6] Massa M \& Simonov A. Reputation and interdealer trading: microstructure Analysis of He Treasury Bond Market[J]. Journal of Financial Markets, 2003 （6） : 99-141.

[7] Ellen Lau, Steve Rowlinson.Interpersonal trust and interfirm trust in construction projects[J]. Construction Management and Economics, 2009, 27 (6) : 539-554.

[8] Ma Huawei, willow, Yao Qi,Review of trust research inter organizationa[J]. 2011, 31 (2): 186-191.

[9] Sekaran. Urea Research on the method of enterprise [M]. Tsinghua University press, Zhu Daosong, Lin Wu, translation, 2005.

[10] Popp L,Zhou K Z,Ryu S, Alternative origins to interorganizational trust :an interdependence perspective on the shadow of the past and shadow of the future. Organization

Science,2008,19(1):39-55. 